\title{
Review of the National Culture Influence on Pilot's Decision- Making during flight: North Africa region prospective
}

\author{
Zakria belaid $^{1}$, Graham Braithwaite ${ }^{2}$, Rashid Hamad ${ }^{3}$ \\ ${ }^{1,2,3}$ School of Aerospace, Transport\& Manufacture. Cranfield University, Bedford, MK430AL
}

\begin{abstract}
Thisreview paperstudies the influence of the national culture onflying safety in the cockpit. Likewise, the study aims toevaluate the pilot behaviour and response to risk during flight in terms of pilot decisionmaking. According to Helmreich (2000), "cultural values are so deeply ingrained; it is unlikely that exhortation, edict, or generic training programs can modify them. The challenge is to develop organizational initiatives that congruent with the culture". Thus,evaluating the technology-culture interference impact on a pilot's decision-making performance, within a specific region gives deep understanding of the pilot's behaviour under the effect of this region national culture. In addition, this appraises the risk tolerance, error management and factors that affect pilot decision-making in regarding to national culture within the region.The expected contribution of this research is to enhance the pilot decision-making performance within the region of North Africa. Moreover, this study will enhances the implementation of Crew Resource Management training program $(C R M)$, in which will support the culture calibration of the CRM tofit the pilot'sneeds within this region. Ultimately, a safe operation of the aircrafts and improvethe aviation marketwithin the region.
\end{abstract}

Keyword:national culture, organisation culture, decision-making, risk perception, crew resource management $(C R M)$.

\section{Introduction}

In high-risk industries, the influence of the surrounding environment, culture and organisational factors on individual behavior has been a vital issue. This is because of the high rate of human-error and accidents, which can take place in an organisational context [34]. The aviation sector is an example of a high-risk industry, in which machine-related accidents have decreased because of cutting edge-technology and the complex systems found in these organisations. In contrast, however, the frequency of human error has increased [47]. Humanerror-related accidents have recently become more familiar in the aviation industry [34]. Thus, to minimise pilot error, a high level of safety and reliability must be installed in aviation companies.

Moreover, distinguishing organisational criteria that enhances high safety reliability, safety performance and low rates of pilot error can enhance theunderstanding of the relationship between pilot behavior and established high-risk situations [54]. Likewise, the behaviour of the pilots is crucial in maintaining high safety performance which can be influenced by initiating a positive organisational safety culture [35]. Helmreich and Merritt (2001) have traced factors that can affect an individual's safety behaviour like national, professional, and organisational factors and insisted that a strong and positive organisational safety culture can help to successfully achieve and improve safe behaviour in the workplace.According to this, the identification of organisational factors which affect safety behaviour among pilots who are performing in high-risk situations is crucial in establishing a positive safety culture [54].

Hence, the pilot's behaviour and response to any event, depending on how they perceive their work environment and the situation have a key role in making decisions about how they are going to behave. According to (Wilde, 1982),improvements in safety operation cannot be achieved through training, engineering or enforcement, but rather through reducing the extent of risk taking which depends on the values that prevail, not the safety technology available. Safety interventions need to consider risk perception and reduce the level of risk that people are willing to tolerate, if they want to be successful[61]. Therefore, ntional culture have a great effect on the pilots' decisions, responses and management of the situation

\section{Aviation Safety Evolution}

The evaluation of aviation safety has gone through several stages which will be evident through the literature. It will be divided into three phases of error causation: technical factors, human factors and organizational factors [34]. Figure (1) illustrates these stages more clearly. Throughout the early years of the evolution of aviation safety, as mentioned above, most researches focused on deficiencies within safety that were primarily because of technical factors and technological collapse rather than human errors [59]. In most cases, human factors are identified as the reason behind aviation accidents for several reasons; including the fact that legal responsibility is more easily assigned to individuals than companies. Secondly, linking an individual's error to an accident can be more clearly observed. Thirdly, due to the lack of observation in the nature of the 
relation between accidents and organisational variables, the number of studies manifesting organisational failures is consequently limited [24].

Lastly, putting the blame on individuals rather than corporations has brought financial profit to organisations. Nonetheless, the impact of organisational influences on the complex nature of accidents related to human error has recently been recognised by researchers [20].Accident causation and classification models have been developed by researchers in this field to demonstrate the influence of organisational variables over individual behaviour which will be discussed in the following paragraphs, leading to an improved understanding of accident causation.

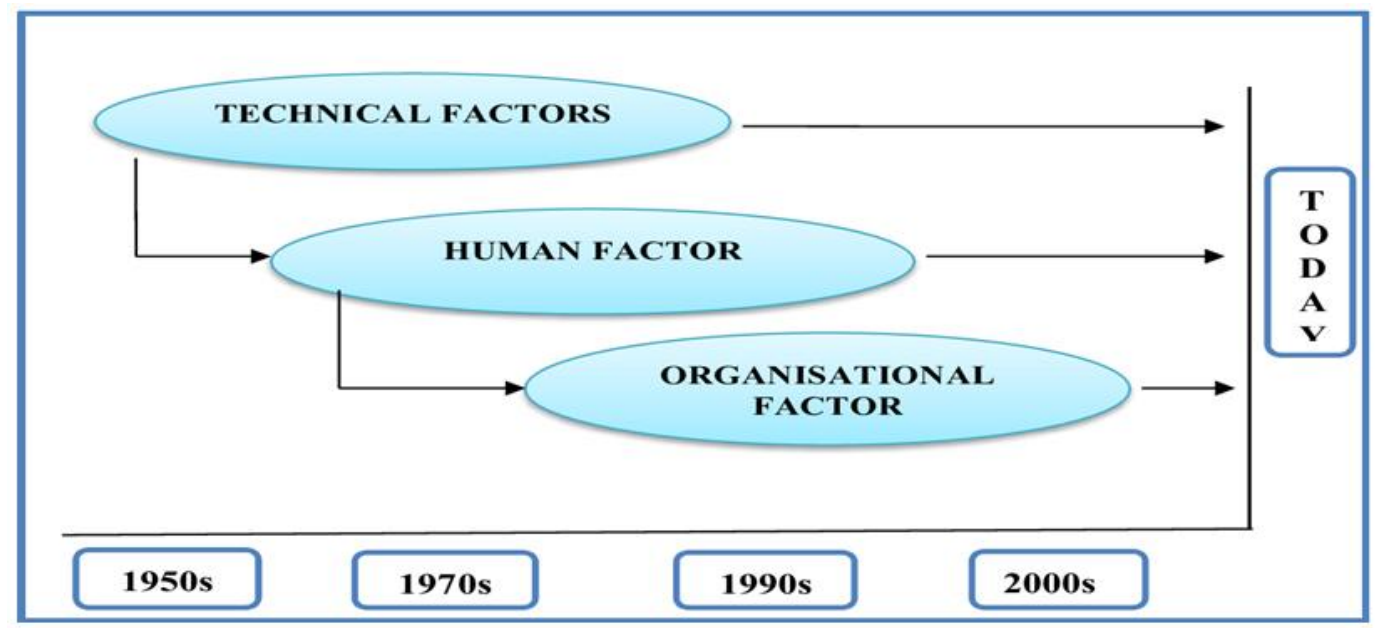

Figure (1): Evolution of safety [24].

\section{Aviation accident and incident causation}

Several factors may contribute to aviation accidents. One of these factors is human error. The definition of human error is "inappropriate human behavior that lowers levels of system effectiveness or safety, which may result in an accident or injury", [10]. In the field of aviation, human errors are considered the most frequent factor contributing to aircraft accidents. Human errors may include the errors of pilots, maintenance staff, air traffic controllers, or others who have a direct effect on flight safety. Approximately $80 \%$ of aircraft accidents are a result of human errors and most of these accidents are caused by pilot errors [47].According to Diehl et al, (1987), once the government licenses a pilot, they are expected to obey the regulations and refrain from any actions which may impact the safety of others. As the regulations note, the pilot should be the final authority for the safe operation of the aircraft. The pilots should be responsible for behavior and utilise "good judgment" in all situations [25]. The decisional activities include self-assessment of skills, knowledge, physical and psychological capabilities, hazard assessment, navigation planning and flight priority adjustment. Pilot errors can happen regardless of intention or skill, but rather more, when they make quick decisional errors. Diehl et al (1987) describes "their skills or luck is often sufficient to get them out of situations resulting from poor judgment". Decision-making is a process of applying an action, attention and access to information stored and collected in memories [10]. According to Gerard J, Fogartyand Shaw (2010), cognitive biases, physical condition, and attitudes can affect the success of the decision-making process. Some researchers such as Gibbs and Olson (2008) and Shappellet al, (2007) conducted studies to analysethe causes of aviation accidents and most of them found that decision making played a major role in these accidents.

Gibbs and Olson (2008) conducted a study to analyse 124 U.S. Air Force aviation accidents from 1992 through 2005 and they found most types of accidents included controlled flight into terrain (CFIT), loss of control and that 48 of the total 124 accidents can be attributed to CFIT. The study found that decision-making errors were the reasons for 40 of the 48 accidents. Another study conducted by Shappellet al, (2007) analysed the accidents associated with two types of commercial aviation.

The study showed that $56.5 \%$ associated issues to skills- based error, $36.7 \%$ related to decisionmaking, and $23.1 \%$ contributed to violations.However, some have argued that decision making and violations are the same. According to Lindvall (2011), one reason for accidents was that people occasionally decide to deviate from safe operating procedures, or rules. Therefore, it might make sense to combine violations of rules with decision-making. Thus decision-making processes combined with violations would be one of the most prominent reasons for accidents. 


\section{Aviation Human Error}

The main contributing factors of accidents and incident in the aviation field are human error [8]. Industries using high risk technology like nuclear power, oil production and aviation are more prone to human errors [4]. To understand why significant amounts of human errors are occurring within these complex industries, a large body of research has been published. Although organisational factors are well known topics and have a significant influence on safety process, such as organisational culture, safety behaviour, and safety performance, these have not been sufficiently appreciated in the research studies [6].

It is important to note that human errors can be widely determined in the ways that individuals are most likely to be affected in the application of their judgments. Berlin et al, (1982) stated that a pilot's decisional errors were attributed to his or her attitude, with the cause originating from pilots selecting inappropriate actions in the light of additional information that might have convinced them to select another option. Therefore, organisations should probably aim to focus on the modification of their workers' attitudes and behavior in order to improve flight safety. If decision-making could be influenced by personal attitudes therefore; consequently, safety may be improved by modifying those attitudes. Likewise, understanding the deep root of accident causation is crucial in either ways to be mitigated or prevented. In the next paragraphs, some models of accident causation will be more discussion.

In summary, the core causation of error in organisational factors in aviation accidents could remain ignored for a long period by organisational members. Sudden disasters may occur because of inactive and apparently inconsiderable factors, through setting off an action that could lead to the accident.

In addition, aviation organisations are getting more complex due to cutting-edge technology and the development of management systems. The likelihood of vulnerability to accidents is higher in complex organizations than in less complex ones. Therefore, aviation accidents are regarded as inherited "normal accidents" because of the complexity of this industry. Strong management can to a certain extent control inherent failure in complex aviation systems; this management has become more significant in such organisations than in the past. Organisational factors have direct influences onthe decision makers within the organisation, which can instantly affect a pilot's behaviour and decisions; likewise, it is significant to concede organisational processes as well as the organisational climate.

The organisational climate indicates a sequence of organisational characteristics, involving the structure of the organisation, designed policies, and organisational culture. Thus, the climate and culture of an organisation have been described and developed in a parallel way to human error models, because they have alwaysbeen considered as latent factors, which have a direct or indirect effect on decision-making and behaviours. A further detailed explanation for these terms is given in the next paragraphs.

\section{National culture}

According to Sjöberg, (2006), Local culture and societies have many dimensions which influence human attitudes. In addition, the culture can be defined as a pattern of learning behavior for a person's way of life, such as different manners of speaking and responding. Culture have been defined by researchers in many different ways, but the most clear and appropriate is defined by (Hofstede, 1991), in which he stated that culture is "pattern of assumptions, values and beliefs whose shared meaning is acquired by members of a group". Moreover, Hofstede in (1991) argues that culture expresses a person's intentionsbeliefs, attitudes, values and norms. It is clear therefore that a group of people can share the same beliefs, values, institution and rules as a community culture [58]. There is no agreement among researchers about the specific divination of the term culture, but Hofstede's original and pioneering definition (1980) remains the most significant, in which he defined culture as "the collection of program of the mind, which distinguishes the members of one human group from another". In addition, he has built a conceptual framework to clarify this term, which is still considered as a main source of reference for many researchers in this area.

\section{Organisational culture concept}

Culture studies aim to define and analyse the influence of culture over individual-, group- and societal-level behaviours [39]. The Hawthorne studies from the 1920's, which examine individual and group behaviour are regarded as the first systematic qualitative analysis, in spite of the important amount of research that were published during the 1940s and 1950s [31]. Schein (2004) gave a definition of culture combined with a precise description of culture development within an organisation. He believes that organisations are constructed by founders as purposeful objects, who possess solid assumptions about the mechanism of achieving things.

Moreover, they have strong a perspective about reality, human nature, truth, relationships, time, and space as these have a cultural effect which is shared and composed within an organisation[46]. The significance of leadership behaviours, values, and vision in shaping organisational culture, artefacts and values has been given a strong priority by some theorists. Also Schein (2004) defined organisational culture as "a pattern of shared basic assumptions that a given group has invented, discovered or developed in learning to cope with the 
problems of external adaptation and internal integration - a pattern of assumptions that has worked well enough to be considered valid and, therefore, to be taught to new members as the correct way to perceive, think and feel in relation to those problems".

A large number of issues have been covered by this definition and it is apparent that the culture concept is related attitude. Organisational culture has been investigated by other theorists from a limited perspective, mentioning business and industry environments as the essential basis of the phenomenon [39]. A diversity of meanings and patterns has been generated by various prospects in the theoretical frameworks for the construction of organisational culture. Due to the different researches, domains and interests of the theorists, the content of organisational culture has taken different shapes. Culture has three hierarchical layers: artefacts, values, and basic assumptions [46].

Artefacts contain concrete, visible, and audible conclusions of events or considerations of the principles (values) and assumptions of an organisation. Artefacts are mostly represented in observable rituals, ceremonies, technology used, physical environment, uniforms, and furniture [45].

In addition, its comparative importance requires principles and it depends on beliefs or concepts [39]. Values act as a guideline to direct individuals towards the best selection among numerous options; also, they form an evaluation of the beliefs and actions that stand as a demanding role in organisational workers practices [31]. See figure (4) below:

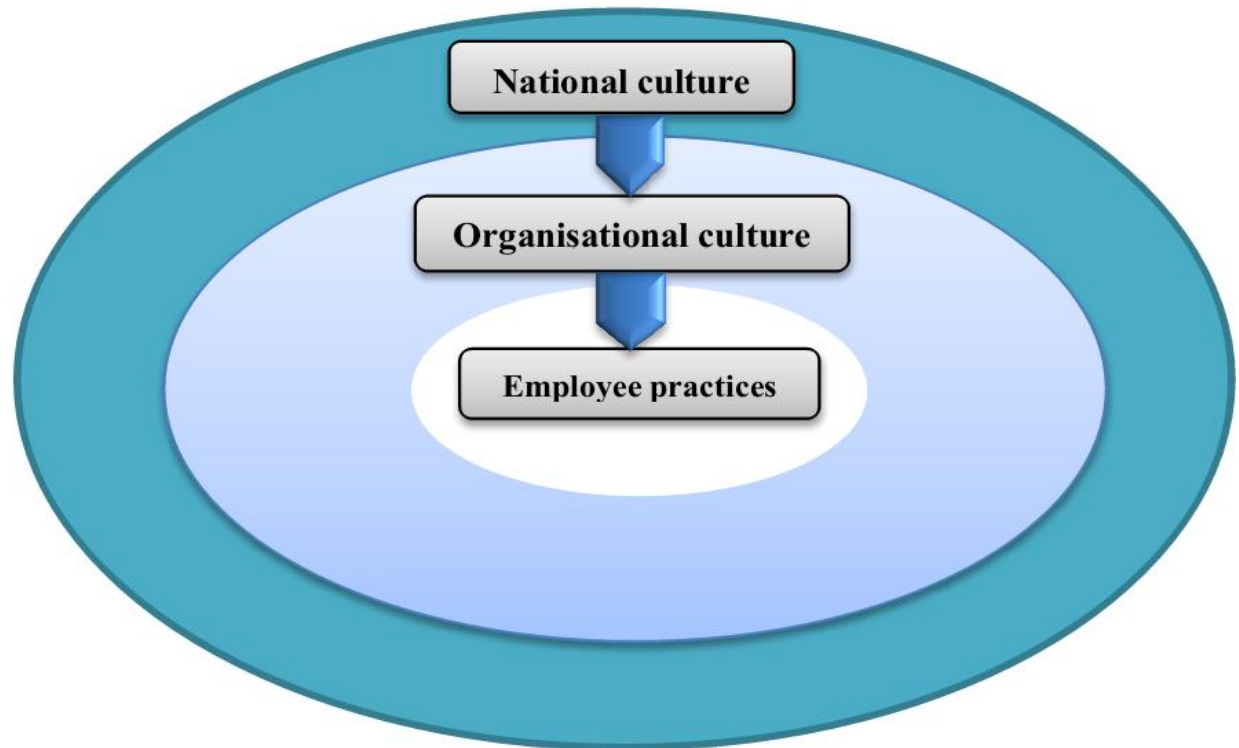

Figure (4): Work practice constituted by culture within an organizational.

According to Schein (2004), the main assumptions form the body of organisational culture, although, it is challenging to observe them precisely. Primarily, it is values that generate assumptions. They cannot be changed easily and are rarely debated. Due to the important role of basic assumptions as a guidance for organisational members to act in a particular manner and rationalise their attitudes according to circumstances, they are therefore of great importance.

The organisational culture can be examined through the organisational climate which represents its codes, values, norms, and rules, its expected and valued behaviours. There is a common confusion between organisational culture and organisational climate, thus it is identify them clearly it terms of safety performance improvement.

\section{Safety behavior and organizational factors}

Organisational factors have a direct effect on the safety behaviour of an individual, which in turn has a significant influence in building a positive safety culture within an organisation. Likewise, human error occurs in the context of an organization rather than in isolated situations [12].As result of the swift development in aviation technology, accidents related to machines have noticeably declined since World War II, while, the increased complexity of aircraft systems and human-error related accidents have risen [59]. Consequently, human errors in aviation are now more frequent than in the early days. Hence, organisational culture has a wide effect on shaping employee's attitudes, which influences values, beliefs, and behaviours; it is crucial therefore to understand the effect of local culture on safety behaviour and promote the factors within an organisational culture that minimise human error and improve organisational performance [5]. 
Furthermore, understanding the effect of the local culture on the safety behaviour of individuals in a highly complex industry helps to shape and systematically design a positive safety culture [11]. Therefore, a positive safety culture can help to reduce both an individual's errors and violations of safety rules within region of North Africa, by creating a good understanding of the non-technical skills (culture awareness) of the pilots, which affect their behaviour (decision making) in response to any incident during the flight, due to human factors or natural events, this will therefore improve their safety performance. In addition, it will help to build a positive safety culture in the North African based aviation companies.

\section{Organizational Safety Culture}

Safety culture concept appeared first time after the disaster of the Chernobyl nuclear power station after the investigation of the accident in the final report, which emphasised that a poor safety culture in the organisation was the main reason for the disaster [2]. Since the disaster, the term safety culture has gained more attention from researchers and has developed a variety of definitions, deriving mostly from the organisational culture literature[56]. Safety culture not only describes the root cause of the disaster, but also describes the organisational culture and environment within which the unsafe behaviour was committed [56].

According to Antonsen (2009) the Advisory Committee on Safe Nuclear Installations (ASCNI) has defined safety culture as one of most frequently cited definitions, which underpins most of the conducted researches as: "The product of individual and group values, attitudes, perceptions, competencies and patterns of behaviour that determine the commitment to, and the style and proficiency of, an organization's health and safety management". Another similar definition proposed by Guldenmund (2000) in order to provide a more concrete vision to of the concept which is: "Those aspects of the organizational culture which will impact on attitudes and behaviour related to increasing or decreasing risk". Antonsen has presenting safety culture in his model (2009) as the organisation's culture that affects safety see figure (5).

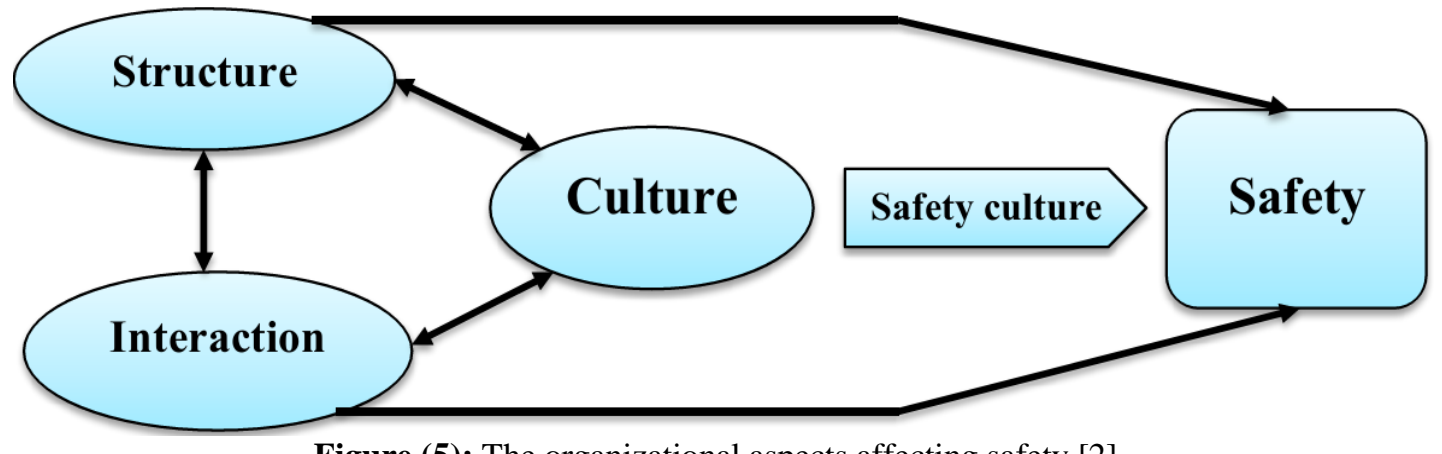

Figure (5): The organizational aspects affecting safety [2].

From the above definition, we can see that the research on the culture of safety organisation expectations aims to be generative. It will, therefore, provide a security approach of the desired effect, as the generative actively involves seeking a new potential for learning in that new ideas are encouraged. Also, the desired effect is not achieved with pathological organisations, which serve to inhibit the generative potential. Safety culture is described as the systematic study of an individual's perceptions about safety within an organisation.

There is no universal agreement about what to include the in the concept of safety culture [2]. However, safety researchers seem to agree that safety culture is about the employees' shared attitudes towards safety and managements' priority of safety within the organisation. Safety culture is also frequently seen as an important organisational antecedent of workers' risk-taking behaviour and propensity to act in accordance with prevailing rules and procedures [57].

Reason (1998) for example, claims that organisations with low standards of safety will encourage an environment of non-compliance to the practices of safe operating. Unsafe behaviour is possibly most common in organizations where the unspoken attitudes and beliefs do not agree with the organisation's safety target. The organisational safety culture concept refers only to aspects that are known in advance and are clearly connected to safety, such as safety training, safety communication and safety values [57].

\section{Individual 's Attitudes toward Safety}

The attitude of an individual regarding safety is attributed to the value of his or her expectancy towards safety [13]. The positive or negative outcome of an individual expectation is inherent within his or her behaviour (Hall $\&$ Silva, 2008). Furthermore, the expected behaviour is based on the individual's subjective value assessment.However, an intended behaviour is also subject to value judgements, leading to the development of an attitude which will derive the behaviour of the expected outcome. According to Hall \& Silva (2008) the strength 
of an individual's attitude, which is based on behavioural beliefs, is dependent on the expected outcome that has relied on subjective evaluation.

Indicators of attitude were designed to evaluate the feeling of an individual regarding risks, safety commitment and safety tool usage and moreover, their attitudes to the necessity of safety errors, safety violations and regulations [13].An individual's attitude is considered to be one of the main factors in constructing a safety climate. Likewise, it is an intention that is predictive in the planned behaviour [1]. In this model the individual's attitude is suggested to be the significant correlation with group norms, workplace pressures and management attitude toward safety.

An individual attitude related to safety will have a direct influence on following procedures of safety and an indirect influence on violation and error behaviours mediated by the intention variable.

\section{Decision Making}

As mentioned before, this study looks at the effect of national culture on decision-making in the cockpit, thus, focussing on decision-making concepts and definitions are crucial to understanding the process of good decision performance. Likewise, there is no agreement among researchers about specific definitions, but according to Klein, (2012) the most popular definition to explain decision making is that it is a process to choose an action that will solve a problem. Another definition from Harris (2012) is that decision-making means choosing the best alternative from to achieve the goal of the decision maker. In addition, Klein, (2012) argues that the decision making process is based on the decision maker's beliefs, values and preferences. Thus, decisionmaking is a process where the decision maker can identify the action or response that can fit the situation with the expecting outcome, based on his or her beliefs, values and preferences, which will lead to a high decision performance. Likewise, this is crucial skill for a pilot in order to respond to any ambiguous or emergency situation.

In summary, decision-making has a direct connection with national culture (Hofstede, 2001), because different national cultures present a variety of decision-making approaches. This prospective view of Hofstede is the main core of this study. It has been found that, different individuals form different cultures will take varied action as a response to any situation, even if they in the same situation. Likewise, a deep discussion will be outlined in the paragraphs following to understand the relation between culture and decision making as mentioned in Hofstede's cultural dimensions, in which will finally lead to better analyses and understanding of the pilot's decision making and judgments while in flight.

\section{Hofstede's framework and decisions making}

As mentioned above, according to Hofstede's (2001), framework, an individual from a different culture is willing to respond and act in a different way even if they are in the same situation as others who do not share their cultural background. Thus, a detailed analysis of the main four dimensions of the Hofstede framework will proceed in order to explore and address the research gap as follows:

Power distance dimension: This dimension expresses the difference in the power distribution within any organisation. For instance, a country with a high level of power distance has a greater focus on its superiors and they are tend to be autocratic rather than being prepared to consult subordinates. In contrast, with respect to a country with low power distance, decision-making can be shared with all levels.

Uncertainty avoidance:Cultures with low uncertainty avoidance are more willing to tolerate risk, whereas in a strong uncertainty avoidance culture, the degree of trust is very low.

Collectivism versus Individualism: According to Hofstede (2001), collectivist societies are more sensitive to the group and its norms; likewise, they are influenced by values in the group, but expect loyalty in return for respecting the group norms. It is in contrast to an individualistic society which is influenced less by groups and focusses more on autonomy, independence and individual interests, so it is expected to have more conflicts in the decision making process. On the other hand, an individually oriented culture is more likely to conduct a rational decision making approach.

Masculinity and Femininity:This dimension shows that people who are more willing to act in individual way tend to be more ambitious and competitive. In contrast, a society with a feminine culture is less influenced by individuals in groups or by the organisational environment.

\section{Naturalistic decision-making}

The emergence of the term Naturalistic decision-makingis traced to a conference in Dayton 1989 [30]. It has been further defined by (Klein, 1998; Wiggins, 2014), as a study to understand how people use their experiences to make a decision in the context of a situation. According to Lipshitz, Klein, Orasanu, \& Salas (2001), the NDM has been divided in to three approaches as follows:

1. All factors that have a direct or indirect effect on an individual during the process of making a decision, such as uncertainty, stress and pressure among others. 
2. The roll of individuals, professionals and experts in the field during the process of decision-making.

3. The importance of concentrating on situation awareness rather than the chosen course of action.

Many decision-making theories have studied the decision-making process but have failed to consider the decision making process in real life. In addition, they were not all adequate for modelling decision-making in naturalistic settings. To this end, Klein (1998) has outlined a recognition primed decision making theory which is the most popular method in this context, therefore a deep discussion in the following paragraphs will aim for a better understanding of the decision making process in complex dynamic settings.

\section{Aeronautical decision-making}

Many researchers have conceptualised the virtue of emphasising problem recognition, problem formulation and as problem solving, which are the main areas of aeronautical decision-making[28]. In addition, it is phrased in a way that readily embraces the notion of decision making as a complex, dynamic process, (Green et al, 1996). Whereas, aeronautical decision-making can be defined as the ability to search for and establish the relevance of all available information regarding flying, to specify alternative courses of action and to determine the expected outcome from each alternative [29].

Moreover, Jensen (1995) considers that the term decision making refers to purely rational information processing. Likewise, Telfer (1989) also argues that decision-making is "the mental process by which pilots recognize, analyse, and evaluate information about themselves, their aircraft, and the operational environment, leading to a timely decision which contributes to safe flight". In addition, the FAA, (1991) defined the ADM as thesystematic approach to the mental processes used by aircraft pilots to consistently determine the best course of action in response to a given set of circumstances.

In summary, there is no consensus among researchers on a specific definition, but it contains no suggestion that decision making is primarily about choosing one course of action from a small set of alternatives.

\section{Risk concept and management}

Risk concept is the link between the probability and severity of harm. It has been found that risk ratings are closely related especially to the perceived probability of harm rather than severity of consequences [7]. Risks are one of the main safety issues in aviation companies, which can give an indication of both threats and loss assets.

There has been a debate concerning physical properties and possibilities of risk identification by human means. According to Miller and Lessard (2007) the identification and measure of risk might not be easy to obtain, but it is not impossible. In practice there is a string connection between the strategy of risk management and organisational behaviour.

Furthermore, risk can be defined is the probability of an event, impact or utility of its outcome[37]. Risk is the distinction between reality and possibility, where risk can be related to the probability of an incident occurring. Risk reflects both the likelihood that harm will occur and its severity [23]. Risk can be manifested in every day decisions and practices. For instance, crossing a road requires a risk assessments and decisions profile the exposed risk on an unconscious level. Risk quantifying can only be gained by probabilities [23].

Hence this factor should be taken into account when undertaking risk management in any organisation. Miller and Lessard (2007) indicate that scientifically, risk is defined as a measure of the probability of occurrence and the severity of adverse effect. Adverse effect indicates an outcome that does not meet the desirable expectations from a failure or risk event. Likewise, risk management is crucial in social sciences to understand how people deal with risk (Fischhoff, 2006), thus, individuals in dealing with risk should be aware of the factors that might affect their risk perception in order to respond in an appropriate way. According to Slovic, (1999), risk is inherently subjective; it is dependent on the individual's culture and mind. Likewise, from this perspective, an individual's attitude, beliefs, feelings and judgments are involved in risk perception, which are considered as social or cultural values [22] [52]. This means that individuals are relying on many dimensions, characteristics or hazards when they evaluate risk.

In summary, the above discussion shows the importance of managing risk within a high risk industry. In addition, it is crucial to understand the relation between risk perception and pilot decision making during the flight, from a culture perspective. It is therefore clear that managing risk within any organisations is very important to keep the level of risk in all operation tasks within an acceptable value, which can be specified by organisational safety goals. Managing risk in critical and important in every day practices which can only be obtained by the assessment and mitigation of risk factors.

\section{Risk perception}

Risk perception is seen as a phenomenon where every group in any different culture aims to cope with some risk and ignore others to maintain their way of life [49]. Likewise, the understanding of the factors that affect 
the risk perception of pilots from different cultural backgrounds is crucial to improve the pilot's decision making performance in any specific country or region [62]. According to Slovic (1987): "technologically sophisticated analysts employ risk assessment to evaluate hazards and the majority of citizens rely on intuitive risk judgments, typically called risk perceptions". In addition (Slovic ,1992) risk perceptions are inherited in people's attitudes, beliefs, feelings and judgments as cultural or social values that have been adapted towards benefit or hazard. Likewise,Slovic, (2000), argued that geography, sociology, political science, anthropology, and psychology made valuable contributions to the study of risk perception.

Moreover, he emphasised that sociological and anthropological studies showed that social and cultural factors deeply affect perception and the acceptance of risk. Psychological studies helped us to understand relationships between risk decisions, heuristics and mental strategies that are used to assess the events and the mediator effects of social influences on risk decisions. This was discovered by studies on political science. There are therefore three basic approaches to study risk perception. These are revealed preference approach, the psychometric approach, and cultural theory.

\section{Risk perception and national culture}

Cultural theory is mainly involved in explaining the collective phenomena of risk perception. The first study of this approach was introduced by Douglas (1966) and then Thompson (1980), where they tried to link risk perception with social and institutional arrangements, rather than the psychometric perspective. According to Sjöberget al, (2004), cultural theory proposes that human attitudes toward risk and danger are heterogeneous and vary according to cultural biases. An individual's cultural bias is linked with the so-called grid and group. The grid refers to the norms and rules. On the other hand, the concept of the group refers to the extent to which a person becomes incorporated into relationships with others.

By linking grid and group, four types of people are specified: hierarchists, egalitarians, fatalists, and individualists. Thus, each group is concerned with a different type of hazards. There have been some critics for this approach. Many researchers argue that cultural theory fails to consider changes in world views overtime, and that it undervalues the dynamic aspects of social life. Individuals might shift from one type to another. Another criticism of this approach is that there exists little empirical evidence to support it [48].

In additionSjöberg (2006) claims that cultural theory is less successful than the psychometric model and less than $20 \%$ of variance of risk perception can be explained by this theory. Despite criticisms, cultural theory has made substantial contributions to risk perception research and has provided different aspects of risk and tolerance. Likewise, this reseach considering the culture theory is crucial in forming the pilot decision-making in the cockpit and must give more attention.

\section{Crew resource management $(\mathrm{CRM}) \&$ national culture}

CRM training programme have been created to improve the non-technical skills for the airlines pilots [44]. Likewise, this programme was designedand implement in USA, to overcome the human factor intricacies among airlines pilots in North America region. According to Wise et al., (2010) it is false notion to ignore the obvious influence of culture on CRM programme. Thus, to accommodate different pilots from different region the training program must culturally calibrated. According to Helmreich\& Merritt, (2001) CRM is innovated by western culture, which will cause clashes with other national culture values and notions.

Moreover, Helmreich (2000) argues that CRM training programme must implemented among airlines companies as management approach to mitigate risk and error management in cockpit. Which will improve the pilot's non- technical skills and consequently enhance the pilot's decision-making [18]. There were many researches studies the important of CRM in its effectives in the cockpit (Helmreich\& Merritt, 2000), one of these study is conducted by Salas, Wilson, Burke, and Burke in (2006) were they reviewed many researches regarding the effectiveness of CRM and they were found that the conflict result among these studies indicates that CRM greatly influenced by culture.

\section{Conclusion}

There arelimited studiesinvestigatingaviation safety in the North Africa region, specially, regarding the humanfactor issues and safety culture, whichprovide insufficient knowledgeand weakness in non- technical skillsamong the pilots within the region, consequently, poor pilot's decision-making performance. This weakens is noticeable in the ICAO annually safety reports, where the difference in numbers and average of fatal accident between the North African region and other regions is very high. This review gives more attention to the national culture effect on pilot's decision-making, where many researches argue that an individual'sdecisionmakingis affected greatly by the surroundedenvironment, community, and specific context.

According to Slovic (2000), the perception of risks varies with both the individual and the context. Therefore, environment, culture and technology are important aspects to identify, in forming the risk perception of pilots in cockpit. In addition,Sjöberg et al. (2004), emphasise that every social group has different perceptions and 
responds in a different way to risk. In addition, Klein (2012), argues that better decision making can be improved within any organisation, if there is a greater respect for expertise and for the tacit knowledge of the skilled workers and supervisors. Thus, the need to explore the influence of the national culture on the pilot's decision-making and error management during flight within the North African region is crucial.

Moreover, enhancingthe understanding of risk tolerance and error management within the region needs more intention. To achieve these objectives a deep researchexploring the actual pilot's risk perception and the factors, which affect the pilot's decision within the region, is crucial to enhance the pilot's non-technical skills, consequently enhancing the pilot's decision making performance.

\section{References}

[1]. Ajzen, I. (2005). Attitudes, Personality and Behavior 2e. McGraw-Hill International.

[2]. Antonsen, S. (2009). Safety Culture Theory, Method and Improvement. Surrey: Ashgate Publishing Company.

[3]. Berlin , J. I., Gruber, E. V., Holmes, C. W., Jensen, P. K., Lau, J. R., Mills, J. W., \& O' Kane, J. M. (1982). Pilot judgment training and evaluation. US Department of Tranportation.Avialable at: Black, T, R. (1999) Doing a quantitative research in the social science. Sage Publications ltd, London.

[4]. Cacciabue, P, C. (2004). Human error risk management for engineering systems: a methodology for design, safety assessment, accident investigation and training. Reliability Engineering and System Safety 83, pp. 229-240.

[5]. Chauvin, C., Lardjane, S., Morel, G., Clostermann, J, P \&Langard' B. ( 2013). Human and organisational factors in maritime accidents: Analysis of collisions at sea using the HFACS. Accident Analysis and Prevention,59, pp. 26-37.

[6]. Cooper, M., \& Phillips, R. (2004). Exploratory analysis of the safety climate and safety behaviour relationship. Journal of Safety Research, 35, pp. 497-512.

[7]. Davidson, S., G \& Moser, S., J. (2008).Rules, regulations, and risk Government vs commercial contracting. Contract Management. Vol. 48, Issue 4, pp. 34- 38

[8]. Dekker, S. (2005). Ten questions about human error: A new view of human factors and system safety CRC. Manvah, NJ: Lawrence Erlbaum Associates Inc.

[9]. Diehl, A. E., Hwoschinsky, P. V., Lawton, R. S., \&Livack , G. S. (1987). Aeronautical decision making for student and private pilots, Program Engineering and Maintenance Service Washington, D.C. 20591. (accessed on 28 February 2015). Available at: http://www.avhf.com/html/Library/ADM_for_Student_and_Private_Pilots.pdf

[10]. Drinkwater, J. L., \& Molesworth, B. R. (2010). Pilot see, pilot do: Examining the predictors of pilots risk management behavior. Safety Science, 48. pp. 1445-1451.

[11]. Evidence centre (2011) Measuring safety culture. Evidence scan, Health Foundation.

[12]. Flin, R. (2007), Measuring safety culture in healthcare: A caseMeasuring safety culture in healthcare: A case for accurate diagnosis. Safety Science, 45, pp. 653-667.

[13]. Fogarty \& Shaw (2009). Safety climate and the Theory of Planned Behaviour: Towards the prediction of unsafe behaviour. Accident Analysis \& Prevention, In Press, Corrected Proof.

[14]. Gerard J. Fogart, Y, Shaw, A. (2010) Safety climate and the Theory of Planned Behavior: Towards the prediction of unsafe behavior. Accident Analysis and Prevention, 42, pp. 1455-1459.

[15]. Gibbs, R. W., \& Olson, W. (2008), Classification of Air Force Aviation Accidents: Mishap Trends and Prevention. International Journal of Aviation Psychology, 18(4), pp.305-325.

[16]. Green, L., Myerson, J., Lichtman, D., Rosen, S., Fry, A., 1996. Temporal discounting in choice between delayed rewards: the role of age and income. Psychol. Aging 11, 79-84.

[17]. Guess, C. (2004). Decision Making in Individualistic and Collectivistic Cultures, Northern Illinois University. Retrieved at https://core.ac.uk/download/pdf/10687043.pdf. Accessed on 22 Jan 2017.

[18]. Harris, D., \& Muir, H. C. (2005). Contemporary issues in human factors and aviation safety. Burlington, VT: Ashgate Publishing Limited.

[19]. Harris, R. (2012) Introduction to Decision Making, Part 1, VirtualSalt. Retrieved at http://www.virtualsalt.com/crebook5.htm. Accessed at Mach 2016.

[20]. Helmreich, R. L., \& Merritt, A. C. (2001). Culture at work in aviation and medicine: National,organizational, and professional influences.2nd edn. Hampshire, UK: Ashgate Pub Ltd.

[21]. Hofstede, G. (1991). Cultures and Organizations. Software of the Mind. McGraw Hill, London.

[22]. Hofstede, G., Hofstede, G. J. \&Minkov, M. (2010). Cultures and Organizations: Software of the Mind (Rev. 3rd ed.). New York: McGraw-Hill.

[23]. Hopkins, A. (2011). Risk-management and rule-compliance: Decision-making in hazardous industries. Safety Science 49 , pp. 110120.

[24]. ICAO (2013) Safety Management Manual (SMM), International Civil Aviation Organization, Doc 9859, 3th edn.

[25]. Ison, D, C. (2015). Comparative Analysis of Accident and Non-Accident Pilots. Journal of Aviation Technology and Engineering. 4:2, pp. $20-31$

[26]. Jensen, R. S., and Bene, R. A. (1977). Judgment evaluation and instruction in civil pilot training. Springfield, VA: National Technical Information Service, Final Report FAA-RD-78-24, 1977.

[27]. Jensen, R.S. (1995), Pilot Judgment and Crew Resource Management, Ashgate, Aldershot, England.

[28]. Klein, G. (2008). 'Naturalistic Decision Making', Human Factors, 50(3), 456-460.

[29]. Klein, G. (2012) Better Decisions: A Two-Way Street, Culture matter. Retrieved at: http://www.spe.org/ogf/print/archives/2012/02/02_12_11_CultureMatters.pdf. Accessed at March 2016.

[30]. Klein, G. A. (1989). Recognition-primed decisions. In W. B. Rouse (Ed.), Advances in man-machine systems research (Vol. 5, pp. 47-92). Greenwich, CT: JAI Press.

[31]. Landy, F. J., \& Conte, J. M. (2010). Work in the 21st century: an introduction to industrial and organizational psychology. Danvers, MA: Wiley-Blackwell.

[32]. Lindvall, J. (2011). Aeronautical decision-making in context: Influence of affect and experience on procedure violations. PhD thesis Available at: https://gupea.ub.gu.se/handle/2077/27956. Accessed on January 2015

[33]. Lipshitz, R., Klein, G., Orasanu, J., \& Salas, E. (2001). Focus article: Taking stock of naturalistic decision making. Journal of Behavioral Decision Making, 14, 331-352. 
Review of the National Culture Influence on Pilot's Decision-Making during flight: North Africa.

[34]. Maurino, D. E., Reason, J., Johnston, N., \& Lee, R. B. (1995). Beyond aviation human factors-safety in high technology systems. Aldershot, UK: Avebury Aviation.

[35]. Mearns, K., Flin, R., Gordon, R., \& Fleming, M. (2001). Human and organizational factors in offshore safety. Work \& Stress, 15, pp. 144-160.

[36]. Merritt, A. C. (1996). National Culture and Work Attitudes in Commercial Aviation: A Cross-Cultural Investigation. PhD in the University of Texas at Austin, 8/96.

[37]. Miller, R. and Lessard, D.(2007) Evolving Strategy: Risk Management and the Shaping of Large Engineering Projects. MIT Sloan School of Management, pp. 4639-07.

[38]. O'Hare, D .. Wiggins, M., Batt, R., \& Morrison, D. (1994). Cognitive failure analysis for aircraft accident investigation. Ergonomics, 37, 1855-1869.

[39]. Ostroff, C., Kinicki, A. J., \&Tamkins, M. M. (2003). Organizational culture and climateHandbook of Psychology: Industrial and Organizational Psychology, 12, pp. 565-593.

[40]. Reason, J. (1990). Human error. New York, NY: Cambridge University Press.

[41]. Reason, J. (2000). Human error: Models and management. British Medical Journal, 320, pp. 768-770.

[42]. Reason, J., Hollnagel, E. and Paries, J. (2006). Revising the 'Swiss cheese' model of accidents. EEC Note No. 13/06. Project Safbuild. A study prepared for EUROCONTROL Expermental Centre. Eurocontrol. France.

[43]. Salas, E., Bowers, C. A., \&Edens, E. (2001). Improving teamwork in organizations: Applications of resource management training. Mahwah, NJ: Lawrence Erlbaum Associates.

[44]. Salas, E., Wilson, K. A., Burke, S., \& Burke, C. S. (2006). Does crew resource management training work? An update, an extension, and some critical needs. Human Factors, 48, 2, 392-412.

[45]. Schein, E. H. (2004). Organizational culture and leadership. San Francisco, CA: Jossey-Bass.

[46]. Schein, E.H. (2010). Organizational culture and leadership. (4th ed.). San Francisco: Jossey-Bass.

[47]. Shappell, S. A., \&Wiegmann, D. A. (2007). The human factors analysis and classification system-HFACS. Office of Aviation Medicine Technical Report no: DOT/FAA/AM-00/7, Civil Aero-medical Institute, Oklahoma City, OK.

[48]. Sjöberg, L. (2006). Will the real meaning of affect please stand up? Journal of Risk Research, 9(2), 101-108.

[49]. Sjöberg, L., Moen, B. and T. Rundmo. (2004). Explaining Risk Perception. An Evaluation of the Psychometric Paradigm in Risk Perception Research. Rotundepublikasjoner: Trondheim.

[50]. Slovic, P. (1987). Perception of risk. Science, 236, 280-285.

[51]. Slovic, P. (1992). Perception of risk: Reflections on the psychometric paradigm. In S. Krimsky\& D. Golding (Eds.), Social theories of risk (pp. 117-152). New York: Praeger.

[52]. Slovic, P. (1999). Trust, emotion, sex, politics, and science: Surveying the risk-assessment battlefield. Risk Analysis, 19(4).

[53]. Slovic, P. (2000). The perception of risk. London: Earthscan Publications Ltd.

[54]. SMICG(2013). Measuring Safety Performance Guidelines for Service Providers. Safety Management International Collaboration Group. Retrieved at: http://www.skybrary.aero/bookshelf/books/2395.pdf. Accessed at February 2015.

[55]. Telfer R. (1989). Pilot decision making and judgement. In RS Jensen (Ed), Aviation Psychology. Aldershot, UK: Gower Technical.

[56]. Tharaldsen, J. E. (2010). "In Safety We Trust": Safety, Risk and Trust in the North Sea. Stavanger: University of Stavanger.

[57]. Vinodkumar, M., \&Bhasi, M. (2010). Safety management practices and safety behaviour: Assessing the mediating role of safety knowledge and motivation. Accident Analysis and Prevention, 42(6), pp.2082-2093.

[58]. Warner-Søderholm, G. (2011). Understanding perceptions of cultural and intracultural societal practices and values of norwegian managers.DBA thesis. Henley Business School, Reading University.

[59]. Wiegmann, D. A., \&Shappell, S. A. (2003). A human error approach to aviation accident analysis: The human factors analysis and classification system. Burlington, VT: Ashgate Publishing Company.

[60]. Wise, J. A., Hopkin, V. D., \& Garland, D. J. (2010). Handbook of aviation human factors (2nd ed.). Boca Raton, FL: Taylor \& Francis Group.

[61]. You, X., Ji, M., \& Han, H. (2013). The effects of risk perception and flight experience on airline pilots' locus of control with regard to safety operation behaviors. Accident Analysis and Prevention, 57, 131-139 